\title{
Attenuation of inhibitory PAS domain protein- induced cell death by synthetic peptides derived from Mcl-1 transmenbrane domain
}

\author{
Shuya Kasai ${ }^{1,2}$, Ken-ichi Yasumoto ${ }^{1}$ and Kazuhiro Sogawa ${ }^{1}$
}

\begin{abstract}
Expression of Inhibitory PAS domain protein (IPAS) induces apoptosis by inhibiting the anti-apoptotic activity of mitochondrial pro-survival proteins including $\mathrm{BCl}-\mathrm{X}_{\mathrm{L}}$ and $\mathrm{Mcl}-1$ through direct binding. Analysis to examine the IPASbinding region in $\mathrm{BCl}-\mathrm{x}_{\mathrm{L}}$ demonstrated that the C-terminal transmembrane (TM) domain is indispensable for the specific binding. A chimeric protein composed of the TM domain of Mcl-1 fused to the C-terminus of Citrine also exhibited a binding affinity to IPAS, and markedly attenuated apoptosis caused by the overexpression of Cerulean-IPAS in SH-SY5Y cells. HIV-1 TAT cell-penetrating peptide-conjugated synthetic peptides that cover whole or parts of the Mcl-1 TM domain showed anti-apoptotic activity in the $\mathrm{CoCl}_{2}$-induced cell death in PC12 cells. Administration of these highly effective anti-apoptotic peptides to mice treated with 1-methyl-4-phenyl-1,2,3,6-tetrahydropyridine (MPTP) that produces a reliable mouse model of Parkinson's disease (PD) decreased neuronal cell loss in the substantia nigra pars compacta. Therefore, the peptides may be considered promising therapeutic agents for neurodegenerative disorders such as PD and stroke.
\end{abstract}

\section{Introduction}

Inhibitory PAS domain protein (IPAS) has been revealed as a bifunctional protein. It not only suppresses the transactivation activity of hypoxia-inducible factor $1^{1}$ but is also involved in the mitochondrial pathway of apoptosis $^{2}$. IPAS was transcriptionally upregulated by oxidative stress-induced and cytokine-induced NF- $\mathrm{kB}$ activation, leading to cell death ${ }^{2,3}$. We previously demonstrated that IPAS was involved in neurodegeneration in a 1-methyl-4-phenyl-1,2,3,6-tetrahydropyridine (MPTP)-induced mouse model of Parkinson's disease (PD), and degraded by activation of the PINK1-Parkin pathway ${ }^{4}$. The pro-apoptotic activity of IPAS depends on direct binding to pro-survival proteins including $\mathrm{Bcl}-\mathrm{x}_{\mathrm{L}}$,

Correspondence: Kazuhiro Sogawa (kazuhiro.sogawa.d8@tohoku.ac.jp) ${ }^{1}$ Department of Biomolecular Sciences, Graduate School of Life Sciences, Tohoku University, Aoba-ku Sendai 980-8578, Japan. ${ }^{2}$ Present address: Department of Stress Response Science, Center for Advanced Medical Research, Hirosaki University Graduate School of Medicine, Hirosaki, Japan Edited by Inna Lavrik
Bcl-w, and Mcl-1 by which their binding activity to Bax was inactivated ${ }^{2}$. Phosphorylation of IPAS by stressactivated MK2 augmented its pro-apoptotic activity by enhancing the binding affinity to $\mathrm{Bcl}-\mathrm{x}_{\mathrm{L}}{ }^{5}$. These molecular mechanisms of apoptosis induction by IPAS are reminiscent of the mechanisms that Bcl-2 homology 3 (BH3)only proteins cause apoptosis ${ }^{6,7}$. However, the BH3 motif, $\mathrm{L}-\mathrm{x}-\mathrm{x}-\mathrm{x}-\mathrm{G}-\mathrm{D}-\mathrm{E}$ ( $\mathrm{x}=$ any amino acid), that is conserved in BH3-only proteins were not found in IPAS ${ }^{2}$. This motif forms an amphipathic alpha-helix to which a hydrophobic cleft formed by $\mathrm{BH} 1, \mathrm{BH} 2$, and $\mathrm{BH} 3$ domains of prosurvival proteins can bind, leading to initiation of apoptosis $^{8}$. Thus, the absence of the motif in IPAS suggested that a different binding mechanism was involved in the association between IPAS and pro-survival proteins.

In this study, we demonstrate that IPAS directly binds to the transmembrane (TM) domain of Bcl- $\mathrm{x}_{\mathrm{L}}$ and Mcl-1. Cell-penetrating HIV-1 TAT-conjugated synthetic peptides containing parts of the Mcl-1 TM sequence showed anti-apoptotic properties in $\mathrm{CoCl}_{2}$-induced apoptosis in

\section{(c) The Author(s) 2021}

(c) (i) Open Access This article is licensed under a Creative Commons Attribution 4.0 International License, which permits use, sharing, adaptation, distribution and reproduction cc) in any medium or format, as long as you give appropriate credit to the original author(s) and the source, provide a link to the Creative Commons license, and indicate if changes were made. The images or other third party material in this article are included in the article's Creative Commons license, unless indicated otherwise in a credit line to the material. If material is not included in the article's Creative Commons license and your intended use is not permitted by statutory regulation or exceeds the permitted use, you will need to obtain permission directly from the copyright holder. To view a copy of this license, visit http://creativecommons.org/licenses/by/4.0/. 
PC12 cells. We also describe that these peptides attenuate cell loss of tyrosine hydroxylase (TH)-positive neurons in the substantia nigra pars compacta $(\mathrm{SNpc})$ of mice treated with MPTP which is most widely used to produce animal models of PD.

\section{Results and discussion}

\section{IPAS-binding region in $\mathrm{BCl}-\mathrm{x}_{\mathrm{L}}$ and $\mathrm{Mcl}-1$}

$\mathrm{Bcl}-\mathrm{x}_{\mathrm{L}}$ consists of four $\mathrm{BH}$ domains and a C-terminal TM anchoring domain (Fig. 1A). We expressed in HEK293T cells a tail-less mutant $\left(\mathrm{Bcl}-\mathrm{x}_{\mathrm{L}} \Delta \mathrm{C}\right)$ of $\mathrm{Bcl}-\mathrm{x}_{\mathrm{L}}$ lacking $\mathrm{C}$-terminal 37 amino acids, which is dispensable for binding to BH3-only proteins, and examined its binding ability to IPAS. Surprisingly, the deletion mutant was unable to bind to IPAS (Fig. 1B). Furthermore, a mutant $\left(\mathrm{Bcl}-\mathrm{x}_{\mathrm{L}} \Delta \mathrm{TM}\right)$ with a shorter deletion of $\mathrm{C}$ terminal 21 amino acids that only cover the TM domain also showed no detectable binding to IPAS. Next, we investigated the binding ability of the TM domain to IPAS by expressing a chimeric protein containing the TM domain fused to the C-terminus of Citrine (a yellow variant of GFP) (Fig. 1C). The protein exhibited binding activity towards IPAS. A similar construct containing the TM domain of Mcl-1 and two amino acids flanking the domain also showed marked binding to IPAS.

\section{Inhibition of IPAS-induced cell death by the Mcl-1 TM domain}

We transiently expressed Cerulean (a cyan variant of GFP)-IPAS in SH-SY5Y cells to induce apoptosis as described $^{4}$, and investigated the cell-protection effect of the $\mathrm{TM}$ domains. Although expression of full-length $\mathrm{Bcl}-\mathrm{x}_{\mathrm{L}}$ fused to Citrine (Citrine-Bcl- $\mathrm{x}_{\mathrm{L}} \mathrm{WT}$ ) without coexpression of Cerulean-IPAS showed no damaging effect on the cells as assessed by immunofluorescent staining of active caspase-3, a single expression of the TM domain of $\mathrm{Bcl}-\mathrm{x}_{\mathrm{L}}$ fused to Citrine (Citrine-Bcl- $x_{\mathrm{L}} \mathrm{TM}$ ) caused enhanced cell death (Fig. 2A). On the other hand, expression of the Citrine-Mcl-1TM exhibited little effect on cell survival. We, therefore, investigated the cell-protection activity of Citrine-Mcl-1 TM against apoptotic cell death caused by Cerulean-IPAS. As shown in Fig. 2B, IPAS-induced cell death was dose-dependently decreased by the coexpression of Citrine-Mcl-1 TM. However, its protective effect was considerably low when compared with that of full-length Mcl-1V (an Mcl-1 isoform that has the same TM sequence as that of Mcl-1). The cause of the low activity was not known, but it suggests that some other parts in the $\mathrm{N}$ terminal cytoplasmic region of $\mathrm{Mcl}-1 \mathrm{~V}$ may play a protective role in IPAS-induced cell death, possibly by assisting the binding process between the TM region and IPAS.

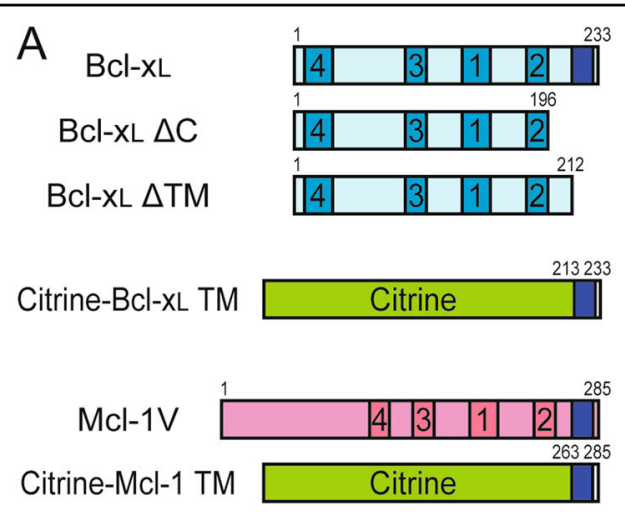

B
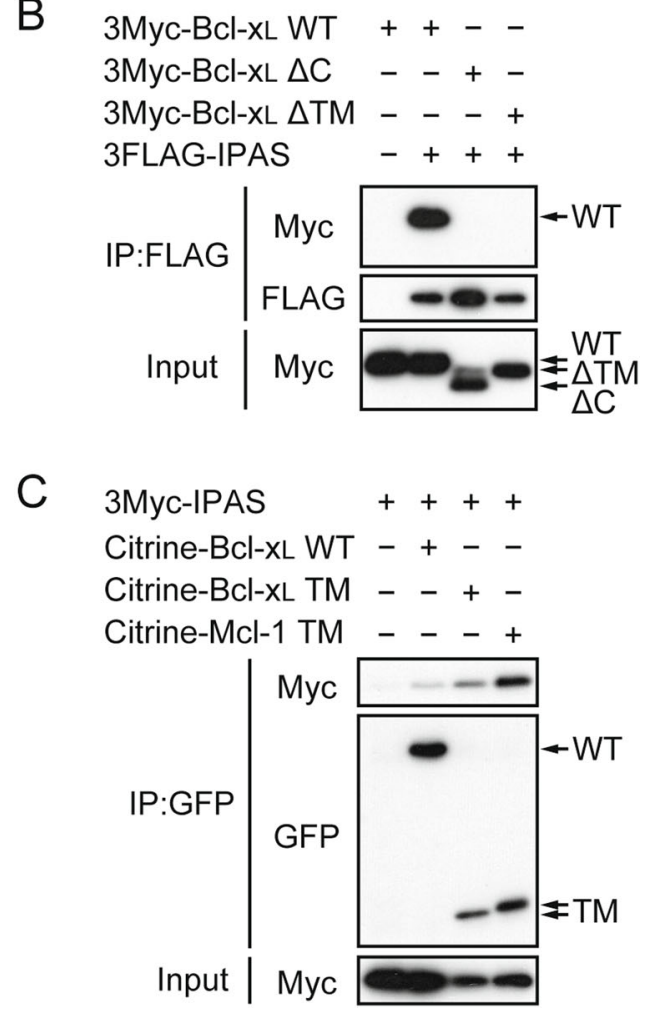

Fig. 1 Binding of IPAS to the TM region of $B c l-x_{L}$ and $M c l-1 . ~ A$ Schematic representation of the structure of $B C l-X_{L}, M c l-1 V$, and their deletion mutants. $\mathrm{BCl}-2$ homology domains, $\mathrm{BH} 1-4$, and $\mathrm{TM}$ regions were indicated by numbered and dark blue boxes, respectively. B Lack of binding of tail-less BCl-X $X_{L}$ to IPAS. HEK293T cells were transfected either with pBOS-3FLAG-IPAS and pBOS-3Myc-BCl-xL WT, pBOS-3FLAGIPAS, and $\triangle C$ or pBOS-3FLAG-IPAS and $\triangle T M$ as described in "Materials and Methods" section. Twenty-four hours after transfection, cellular proteins were extracted and subjected to immunoprecipitation using the antibody against FLAG, and bound $3 \mathrm{Myc}-\mathrm{BCl}-\mathrm{x}_{\mathrm{L}}$ was analyzed by immunoblotting. $\mathrm{C}$ Binding of $\mathrm{BCl}-\mathrm{X}_{\mathrm{L}}$ and $\mathrm{MCl}-1$ TM regions to IPAS. 3Myc-IPAS was coexpressed either with Citrine-BCl- $X_{\mathrm{L}}$ TM or CitrineMcl-1 TM in HEK293T cells and analyzed as in $\mathbf{B}$. 

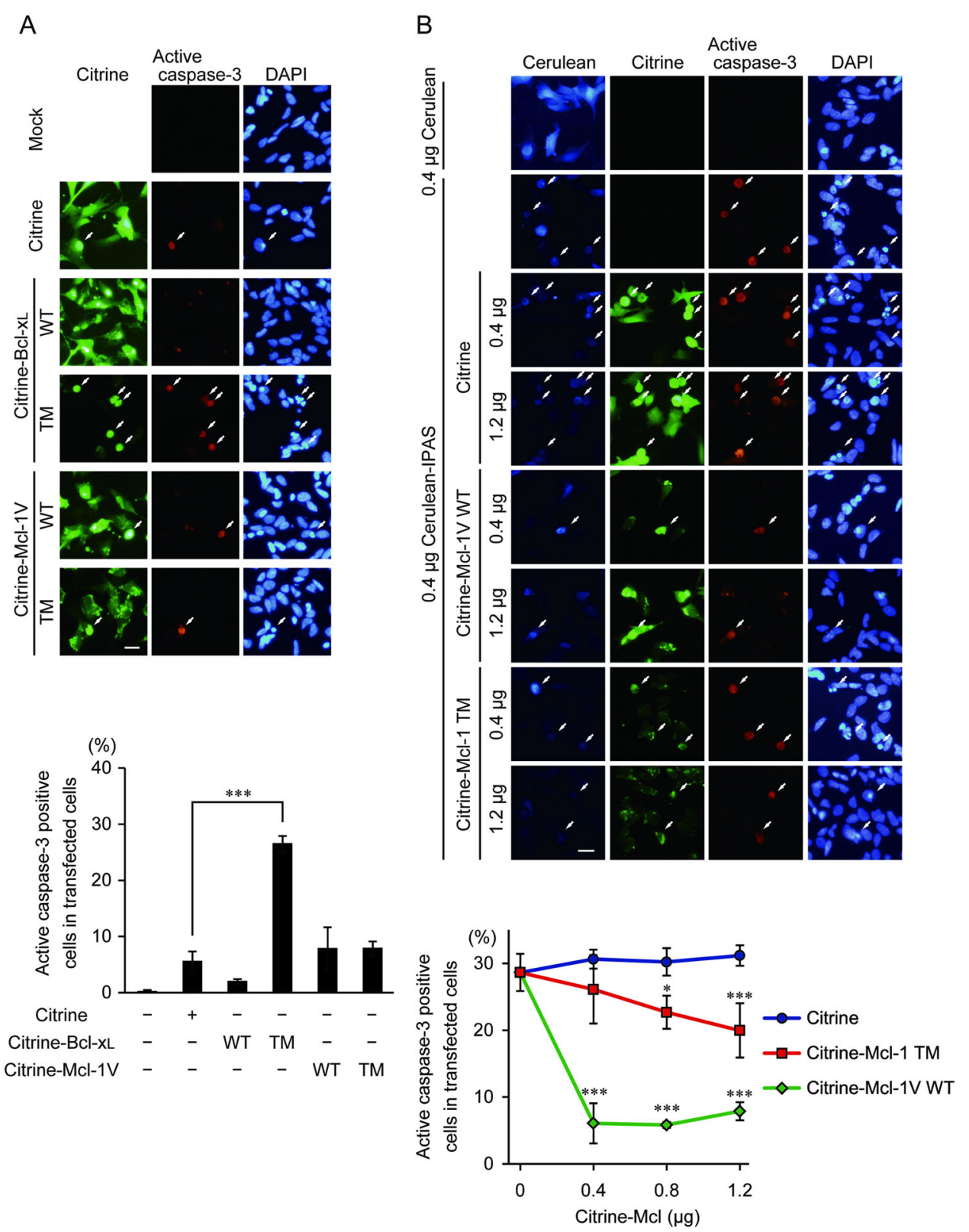

Fig. 2 Suppression of IPAS-induced apoptosis by coexpression of Mcl-1 TM. A Cell toxicity of BCl- $\mathrm{X}_{\mathrm{L}} \mathrm{TM}$ peptide. SH-SY5Y cells in a 12-well plate were transfected with $1.6 \mu \mathrm{g}$ pCitrine- $\mathrm{C} 1$, pCitrine-BCl- $\mathrm{x}_{\mathrm{L}} \mathrm{WT}, \mathrm{TM}, \mathrm{pC}$ itrine-Mcl-1 WT, or TM, and fixed $24 \mathrm{~h}$ after transfection. Apoptotic cells were stained by antibody against active caspase-3. Active caspase-3-positive cells were indicated by the arrows. Scale bar, $20 \mu \mathrm{m}$. The bar graph below represents the percentage of active caspase-3 positive cells detected by the observation of at least 300 transfected cells (mean \pm SD of three independent experiments). ${ }^{* * *} p<0.001$. B Decrease in Cerulean-IPAS induced cell death by the expression of Citrine-Mcl-1V WT or Mcl-1TM. SH-SY5Y cells in a 12-well plate were cotransfected with $0.4 \mu \mathrm{g}$ of pCerulean-C1 or pCerulean-IPAS and $0.4-1.2 \mu \mathrm{g}$ of pCitrine-C1, pCitrine-Mcl-1V WT, or pCitrine-Mcl-1 TM. Apoptotic cells were analyzed as in A. Scale bar, $20 \mu \mathrm{m}$. The line graph below represents the percentage of active caspase-3 positive cells detected by the observation of at least 300 transfected cells (mean \pm SD of four independent experiments). ${ }^{*} p<0.05$, ${ }^{* * *} p<0.001$.

Inhibition of $\mathrm{CoCl}_{2}$-induced cell death in PC12 cells by TATMcl-TM peptides

We previously reported that apoptosis in PC12 cells caused by $\mathrm{CoCl}_{2}$ treatment was IPAS-dependent ${ }^{2}$. Using the cell-based system, we evaluated with the MTT assay the anti-apoptotic activity of peptides derived from the
Mcl-1 TM domain which were conjugated at its $\mathrm{N}$ terminus to the HIV-1 TAT-derived cell-penetrating peptide. The TAT-Mcl-TM1 peptide comprising amino acids -2 to 21 (Table 1 , the $\mathrm{N}$-terminal asparagine residue of the TM domain was numbered as 1) showed a modest protecting activity at concentrations around $2 \mu \mathrm{M}$, 
Table 1 Amino acid sequence of TAT-Mcl-TM peptides.

\begin{tabular}{|c|c|}
\hline Peptides & Amino acid sequence \\
\hline TAT-Mcl-TM1 & $\begin{array}{rrr}-2 & +1 & +21 \\
& \downarrow & \\
\text { YGRKKRRQRRRIRNVLLAFAGVAGVGAGLAYLIR } & \downarrow \\
\end{array}$ \\
\hline TAT-Mcl-TM2 & GRKKRRQRRR - - NVLLAFAGVAGVGAGLAYLIR \\
\hline TAT-Mcl-TM3 & GRKKRRQRRRIRNVLLAFAGVAGVGAG \\
\hline TAT-Mcl-TM4 & GRKKRRQRRR - - NVLLAFAGV \\
\hline TAT-Mcl-TM5 & GRKKRRQRRR - - $\underline{\text { NVLLAFAGVAGVGAG }}$ \\
\hline TAT-Mcl-TM6 & GRKKRRQRRR-- - - - - AGVAGVGAGLAYLIR \\
\hline
\end{tabular}

Peptide sequences underlined are derived from the Mcl-1 transmembrane region.

although it was not statistically significant (Fig. 3A). At higher concentrations, it exhibited toxic effects on the cells. The cytotoxicity of the peptide against HeLa cells was similarly found but very weak against HEK293T cells, suggesting that the cytotoxicity was cell-type specific (Supplementary Fig. 1). TAT-Mcl-TM2 containing only the TM domain showed significant cell protecting activity at higher peptide concentrations $(10-30 \mu \mathrm{M})$ (Fig. 3B). TAT-Mcl-TM5 with deletion of C-terminal 6 amino acids from TAT-Mcl-TM2 also showed a similar protection activity (Fig. 3E). Other deletion peptides (TAT-Mcl-TM4 and TAT-Mcl-TM6) of TAT-Mcl-TM2 exhibited no protective effects on the $\mathrm{CoCl}_{2}$-treated cells (Fig. 3D, F). TAT-Mcl-TM3 containing amino acids -2 to 15 showed a tendency of cell protection at around $2 \mu \mathrm{M}$ and significantly protected cells at concentrations in the range of $5-10 \mu \mathrm{M}$ while it caused cell death at higher concentrations (Fig. 3C).

Inhibitory effects of these TAT-Mcl-TM peptides on the activation of caspase- 3 in $\mathrm{CoCl}_{2}$-treated PC12 cells were investigated (Fig. 3G). Caspase-3 activation was weakly found even in untreated cells, and it was increased by the $\mathrm{CoCl}_{2}$-treatment. The activation was inhibited by the addition of TAT-Mcl-TM2, 3 and 5 while inhibition by TAT-Mcl-TM4 and 6 was very weak. These results were in accordance with those obtained from the MTT assay. The activation of caspase- 3 was not detected in the cells treated with TAT-Mcl-TM1 because protein recovery from the cells was extremely low presumably due to increased cell death. Cellular uptake of the peptides was confirmed by using FITC-labeled TAT-Mcl-TM3. Fluorescence from treated cells was detected in both the cytoplasm and nucleus (Supplementary Fig. 2).

Taken together, these results suggested that the cell protection activity against apoptosis caused by IPAS was localized to the first 15 residues of the TM domain and that the Ile-Arg sequence localized from -2 to -1 also played an important role. The addition of the two amino acids also created cytotoxicity against the PC12 cells. We previously reported that phosphorylation of IPAS at Ser184 enhanced binding affinity to $\mathrm{Bcl}-\mathrm{x}_{\mathrm{L}}{ }^{5}$. This phosphorylated Ser might interact with the Arg residue localized at position -1 because no other positively charged residues were present in the sequence found in this experiment.

\section{Attenuation of neuronal cell loss in the mouse model of PD by TAT-Mcl-TM peptides}

We previously clarified that cell death of dopaminergic neurons in an MPTP mouse model of PD was partly IPAS-dependent ${ }^{3}$. Using the same model, the cellprotection activity of TAT-Mcl-TM peptides was investigated. The treatment schedule of MPTP-intoxicated male mice with TAT-Mcl-TM peptides is shown in Fig. 4A. A single intraperitoneal administration of TAT-MclTM3 showed the tendency of protection toward MPTPinduced cell loss of tyrosine hydroxylase $(\mathrm{TH})$-positive neurons in the SNpc (Fig. 4B, C). Twice-daily intraperitoneal administration of the peptide at the $6 \mathrm{~h}$ time interval significantly attenuated the neuronal cell loss. A similar positive result was obtained when protective effects of TAT-Mcl-TM3 were examined in the different raising environments with elevated ambient temperature (Supplementary Fig. 3). We next examined the effect of TAT-Mcl-TM2 (Fig. 4B and C) on cell loss. It also exhibited a tendency of protection although it was not significant. Taken together, these results demonstrate that TAT-Mcl-TM peptides are protective agents against neurodegeneration in the SNpc caused by MPTP.

It was clarified that the C-terminal TM domain of Bcl$\mathrm{x}_{\mathrm{L}}$ and Mcl-1 was important for binding to IPAS (Fig. 1). This binding mode is totally different from that between BH3 only proteins and pro-survival $\mathrm{Bcl}-2$ family proteins including $\mathrm{Bcl}-\mathrm{x}_{\mathrm{L}}$ and Mcl-1. In a survey of Bcl- $\mathrm{x}_{\mathrm{L}}$-binding proteins, Praf2, a small transmembrane protein that may be involved in transport from the endoplasmic reticulum to the Golgi apparatus, was found ${ }^{9}$. Bcl- $\mathrm{x}_{\mathrm{L}}$ also binds to Praf2 mainly through the TM domain of $B c l-x_{L}$, and through this specific interaction, Praf2 causes cerulenininduced apoptosis in neuroblastoma cells. Similarly, the SARS-CoV protein $7 \mathrm{a}$ can induce caspase-dependent apoptosis in several cell lines via its interaction with the $\mathrm{TM}$ domain of $\mathrm{Bcl}-\mathrm{x}_{\mathrm{L}}{ }^{10}$. Apparent sequence similarity was not observed among IPAS, Praf2, and SARS-CoV protein $7 \mathrm{a}$ although they interact with the same TM sequence of $\mathrm{Bcl}-\mathrm{x}_{\mathrm{L}}$. There may be a large group of pro-apoptotic proteins that interact with the TM domain of pro-survival proteins and act in the early stages of the various apoptosis pathways. More extensive and detailed investigations are necessary to gain a further understanding of this type of pro-apoptotic protein.

IPAS is a downstream effector of NF- $\mathrm{kB}$ in neuronal apoptosis. Activation of NF-kB was found in the dopaminergic neurons of post-mortem PD brains ${ }^{11}$, and several studies reported that inhibition of the classical NF- $\kappa \mathrm{B}$ activation pathway slowed the progression of PD in mouse 


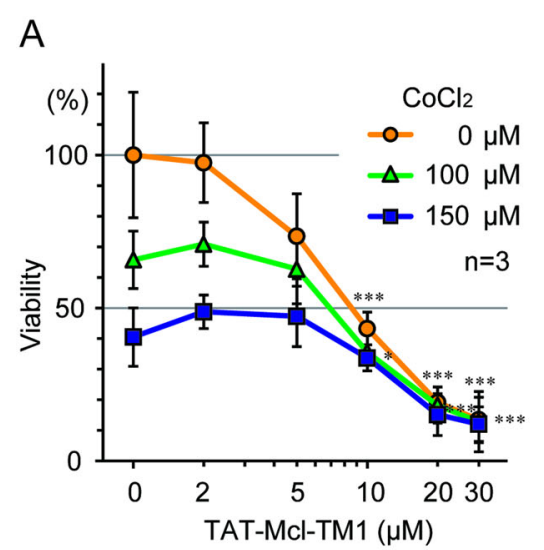

B

C
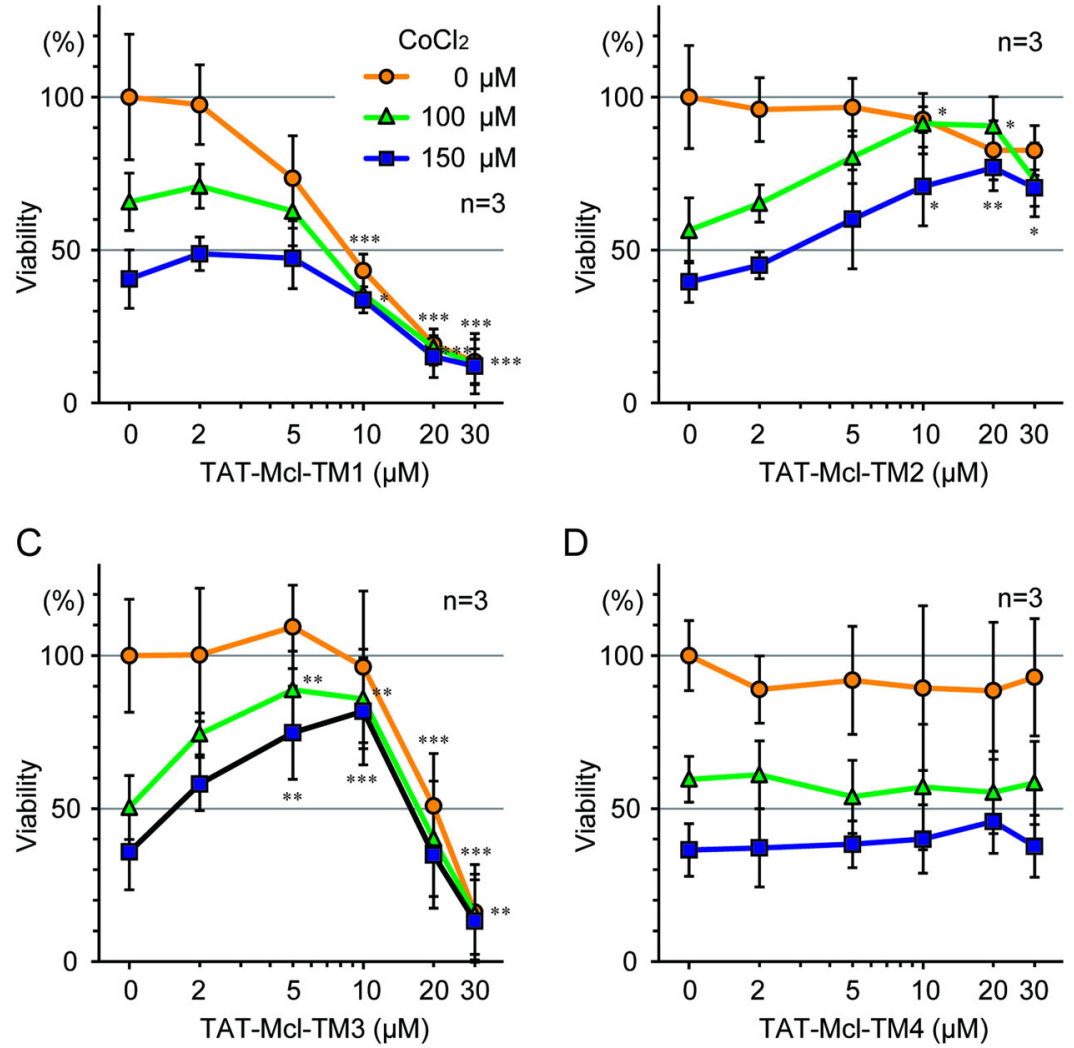

D

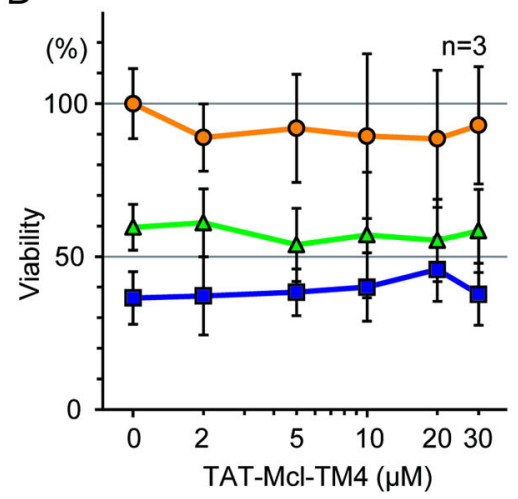

E

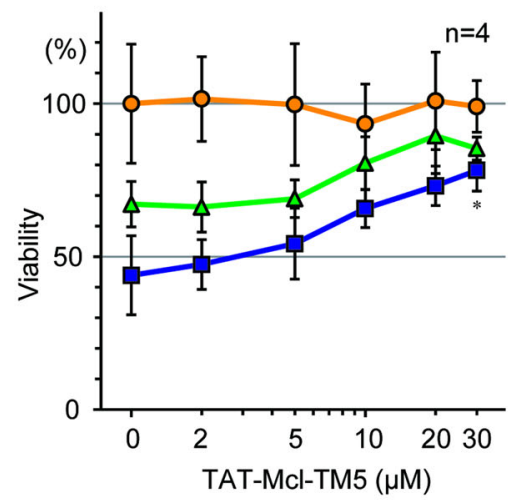

F

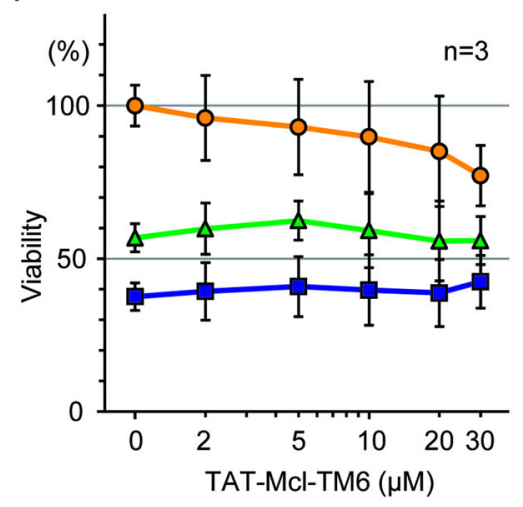

G

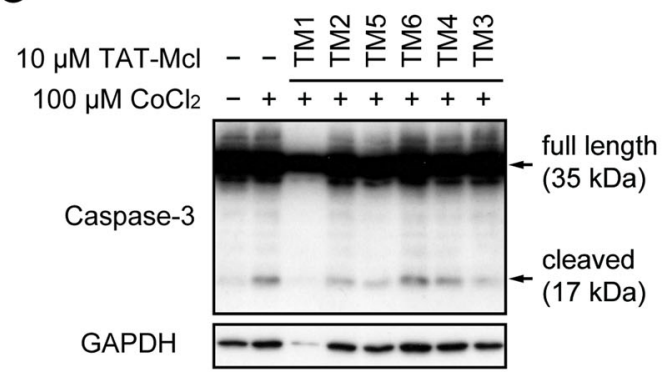

Fig. 3 (See legend on next page.) 
(see figure on previous page)

Fig. 3 Inhibition of $\mathrm{CoCl}_{2}$-induced apoptosis in PC12 cells by the treatment with TAT-Mcl-TM peptides. A-F Viability of $\mathrm{CoCl} 2$-treated PC12 cells pretreated with TAT-MCl-TM-derived peptides. PC12 cells were transduced with 2-30 MM TAT-MCl-TM1 (A), TM2 (B), TM3 (C), TM4 (D), TM5 (E), or TM6 (F) for $2 \mathrm{~h}$. Media were replaced with fresh media containing 0, 100, or $150 \mu \mathrm{M} \mathrm{CoCl}$, and cells were incubated for $16 \mathrm{~h}$. Cell viability was determined by MTT assay, and data are expressed as mean \pm SD from at least three independent experiments. ${ }^{*} p<0.05,{ }^{* *} p<0.01,{ }^{* * *} p<0.001$. G Reduction of caspase-3 activation in $\mathrm{CoCl}_{2}$-treated PC12 cells by TAT-Mcl-TM peptides. PC12 cells were transduced with TAT-Mcl-TM peptides $(10 \mu \mathrm{M})$ for $2 \mathrm{~h}$ and then treated with $100 \mu \mathrm{M} \mathrm{CoCl}$ for $16 \mathrm{~h}$. Cellular proteins were extracted from whole cells and subjected to immunoblotting to detect intact $(35 \mathrm{kDa})$ and cleaved active caspase-3 $(17 \mathrm{kDa})$. GAPDH was detected as the loading control.

and primate models ${ }^{12}$. In addition to $\mathrm{PD}$, ample evidence was also found for an association between activation of NF$\kappa \mathrm{B}$ and progression of cerebral ischemia ${ }^{13}$. It has been reported that administration of TAT-conjugated Bcl- $x_{\mathrm{L}}$ protein has a protective effect against neuronal cell death in the mouse model of middle cerebral artery occlusion ${ }^{14,15}$. Although the studies did not identify a target molecule(s) of TAT-Bcl- $x_{L}$ in the neuron, IPAS could be a potent target. Activation of NF- $\mathrm{KB}$ is also suggested in many neurodegenerative diseases such as Alzheimer's disease (AD) and multiple sclerosis (MS ${ }^{16,17}$. Mcl-TM peptides conjugated to cell-penetrating peptides may be useful for the treatment of these neurodegenerative diseases.

It would be possible to produce improved Mcl-TM peptides with higher affinity to IPAS and without cytotoxicity by introducing point mutations using natural and unnatural amino acids in the TM sequence. The binding of the TM domain to IPAS strongly suggests that a hydrophobic groove that accommodates hydrophobic TM helices is present on the surface of IPAS. Small-molecule inhibitors that fit the hydrophobic groove could also be used for the treatment of NF-kB-dependent neurodegenerative diseases.

\section{Materials and methods}

\section{Reagents and antibodies}

TAT-Mcl-TM1 peptide (the sequence is shown in Table 1) was synthesized as TFA salt by Peptide Institute (Osaka, Japan). The other peptides were synthesized as $\mathrm{HCl}$ salt by GenScript (Piscataway, NJ, USA). TAT-MclTM peptides were dissolved in Milli $Q$ water as concentrated as possible, handled in protein LoBind tubes (Eppendorf, Hamburg, Germany), and stored at $-80^{\circ} \mathrm{C}$. MPTP and antibodies against FLAG and TH were obtained from Sigma-Aldrich (St. Louis, MO, USA). All other antibodies used were purchased from the following sources: anti-Myc (MBL, Nagoya, Japan); anti-Bcl- $\mathrm{x}_{\mathrm{L}}$ (Cell Signaling Technology, Danvers, MA, USA); anti-caspase-3 (Promega, Fitchburg, WI, USA); anti-GFP (Clontech, Palo Alto, CA, USA).

\section{Plasmid construction}

Plasmids for 3Myc-IPAS, 3FLAG-IPAS, Cerulean-IPAS, $3 \mathrm{Myc}-\mathrm{Bcl}-\mathrm{x}_{\mathrm{L}}$, Citrine-Bcl- $\mathrm{x}_{\mathrm{L}}$, and Citrine-Mcl-1V were constructed as described ${ }^{2}$. pBOS-3Myc-Bcl- $\mathrm{x}_{\mathrm{L}} \Delta \mathrm{C}$ (1-196) and $\mathrm{pBOS}-3 \mathrm{Myc}-\mathrm{Bcl}-\mathrm{x}_{\mathrm{L}} \Delta \mathrm{TM}$ (1-212) were constructed by PCR using mouse Bcl- $\mathrm{x}_{\mathrm{L}}$ cDNA and following primers: Bcl- $x_{L}-1-F$, 5'AATTG ATATC ATGTC TCAGA GCAAC CGGG-3'; Bcl- $x_{\mathrm{L}}$-196R, 5'-AATTG ATATC TCACC CGTAG AGATC CACAA AAGT-3', and Bcl- $\mathrm{x}_{\mathrm{L}^{-}}$ 212R, 5'-ATGCG ATATC TCAGC GGTTG AAGCG CTCCT-3'. pCitrine-Bcl- $x_{\mathrm{L}}$ TM (213-233) and pCitrineMcl-1 TM (263-285) were constructed by insertion of the following linkers into the Bgl II-EcoR I site of the pCitrineC1 vector: Bcl- $\mathrm{x}_{\mathrm{L}}$-213-233F, 5'-GATCT TGGTT CCTGA CGGGC ATGAC TGTGG CTGGT GTGGT TCTGC TGGGC TCACT CTTCA GTCGG AAGTG AG-3'; Bcl$\mathrm{x}_{\mathrm{L}}$-213-233R, 5'-AATTC TCACT TCCGA CTGAA GAGTG AGCCC AGCAG AACCA CACCA GCCAC AGTCA TGCCC GTCAG GAACC AA-3'; Mcl-1-263285F, 5'-GATCT ATCAG GAATG TGCTG CTGGC TTTTG CAGGT GTTGC TGGAG TAGGA GCTGG TTTGG CATAT CTAAT AAGAT AGG-3' and Mcl-1263-285R, 5'-AATTC CTATC TTATT AGATA TGCCA AACCA GCTCC TACTC CAGCA ACACC TGCAA AAGCC AGCAG CACAT TCCTG ATA-3'. Constructions were confirmed by sequencing.

\section{Cell culture and DNA transfection}

HEK293T, SH-SY5Y, PC12, and HeLa cells were obtained from the Cell Resource Center for Biomedical Research, Tohoku University, Sendai, Japan, and maintained as described previously ${ }^{2,4}$. HEK293T cells plated in 60-mm dishes were transfected with a mixture of two plasmids $(1 \mu \mathrm{g}$ each) using Lipofectamine 2000 (Invitrogen, Carlsbad, CA, USA) according to the manufacturer's instructions.

\section{Immunoprecipitation and immunoblotting}

At $24 \mathrm{~h}$ posttransfection, cells were harvested and cellular proteins were extracted and subjected to immunoprecipitation using an antibody against FLAG or GFP. The immunoprecipitates were analyzed by western blotting using the indicated antibodies as described previously ${ }^{5}$.

\section{MTT assay}

HeLa cells were seeded at $10^{4}$ cells/well in a 96-well plate. PC12 and HEK293T cells were seeded at $4 \times 10^{4}$ or $10^{4}$ cells/well, respectively, in PEI-coated 96-well plates. After overnight incubation, cells were treated with 2-30 $\mu \mathrm{M}$ peptides diluted in Opti-MEM for $2 \mathrm{~h}$. Media 


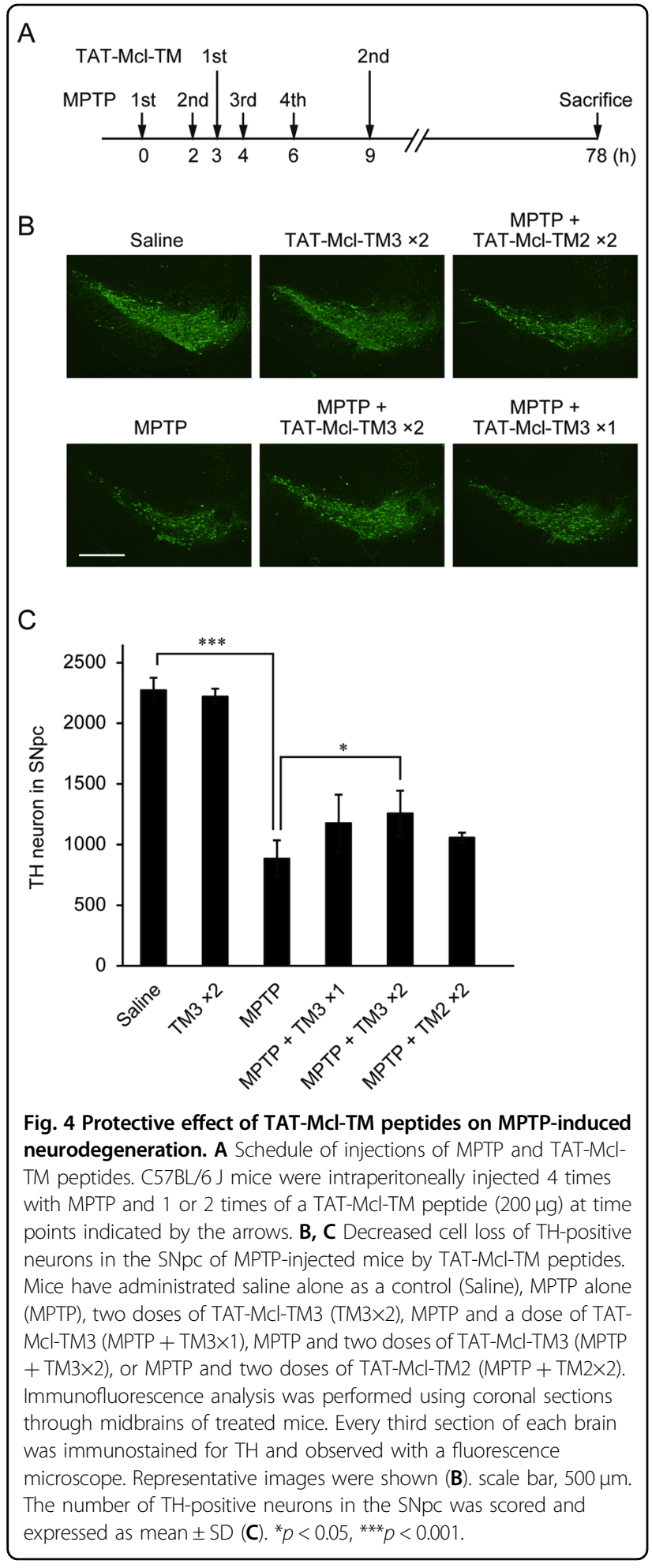

were replaced with serum-containing RPMI 1640, and cells were treated with 100 or $150 \mu \mathrm{M} \mathrm{CoCl}_{2}$ for $16 \mathrm{~h}$. After washing with PBS, cells were incubated in $0.5 \mathrm{mg} / \mathrm{ml}$ MTT (Dojindo, Kumamoto, Japan) in culture media for $3 \mathrm{~h}$. MTT formazan was dissolved in dimethyl sulfoxide and photometrically quantified at $535 \mathrm{~nm}$. The toxicity of peptides was calculated as described ${ }^{18}$.

\section{Animals}

Male 9-12 weeks old C57BL/6J mice obtained from Japan SLC (Hamamatsu, Japan) were bred in a 12-h light/ 12-h dark cycle at $23^{\circ} \mathrm{C}$. All animal experiments were approved by the Committee for Animal Research of Tohoku University and performed in accordance with the Regulation for Animal Experiments and Related Activities as Tohoku University (Regulation No 122). Mice were injected 4 times with $15 \mathrm{mg} / \mathrm{kg}$ MPTP intraperitoneally at a 2-h interval. TAT-Mcl-TM peptides were diluted with saline and injected intraperitoneally at $3 \mathrm{~h}$ and $9 \mathrm{~h}$ after the first MPTP injection. Mice were sacrificed by inhalation of isoflurane $72 \mathrm{~h}$ after the last MPTP injection.

\section{Immunofluorescent staining}

SH-SY5Y cells grown on coverslips in a 12-well plate were mock-transfected or transfected with $1.6 \mu \mathrm{g}$ pCitrineC1, pCitrine-Bcl- $x_{\mathrm{L}}$ WT, TM, pCitrine-Mcl-1V WT, or TM. Cells were fixed $24 \mathrm{~h}$ after transfection and stained with antibody against active caspase- 3 as described previously ${ }^{4}$. Preparation of formalin-fixed paraffin-embedded brain sections and succeeding immunofluorescence staining of the sections using anti- $\mathrm{TH}$ antibody were carried out as described ${ }^{4}$.

\section{Statistical analysis}

Multiple comparisons were analyzed by two-way ANOVA followed by post hoc Tukey-Kramer test.

\section{Acknowledgements}

We thank $\mathrm{H}$. Inabe for his technical assistance.

\section{Author contributions}

S.K., K.Y., and K.S. planned experiments; S.K. performed experiments; S.K. and K. S. analyzed data, and K.S. wrote the paper.

Conflict of interest

The authors declare no competing interests.

\section{Publisher's note}

Springer Nature remains neutral with regard to jurisdictional claims in published maps and institutional affiliations.

Supplementary information The online version contains supplementary material available at https://doi.org/10.1038/s41420-021-00475-3.

Received: 18 February 2021 Revised: 30 March 2021 Accepted: 3 April 2021 Published online: 04 May 2021

\section{References}

1. Makino, Y. et al. Inhibitory PAS domain protein is a negative regulator of hypoxia-inducible gene expression. Nature 414, 550-554 (2001).

2. Torii, S. et al. Pro-apoptotic activity of inhibitory PAS domain protein (IPAS), a negative regulator of $\mathrm{HIF-1}$, through binding to pro-survival $\mathrm{BCl}-2$ family proteins. Cell Death Differ. 18, 1711-1725 (2011). 
3. Goryo, K., Torii, S., Yasumoto, K. I. \& Sogawa, K. Tumour necrosis factor-a suppresses the hypoxic response by NF-KB-dependent induction of inhibitory PAS domain protein in PC12 cells. J. Biochem. 150, 311-318 (2011).

4. Torii, S. et al. Involvement of Inhibitory PAS domain protein in neuronal cell death in Parkinson's disease. Cell Death Discov. 1, 15015 (2015).

5. Kasai, S. et al. Increase in proapoptotic activity of inhibitory PAS domain protein via phosphorylation by MK2. FEBS J. 284, 4115-4127 (2017).

6. Lomonosova, E. \& Chinnadurai, G. BH3-only proteins in apoptosis and beyond: an overview. Oncogene 27, S2-S19 (2008).

7. Doerflinger, M., Glab, J. A. \& Puthalakath, H. BH3-only proteins: a 20-year stocktake. FEBS J. 282, 1006-1016 (2015).

8. Muchmore, S. W. et al. X-ray and NMR structure of human BCl-X of programmed cell death. Nature 381, 335-341 (1996).

9. Vento, M. T. et al. Praf2 is a novel $\mathrm{BCl}-\mathrm{xL} / \mathrm{BCl}-2$ interacting protein with the ability to modulate survival of cancer cells. PLOS ONE 5, e15636 (2010).

10. Tan, Y.-X. et al. Induction of apoptosis by the severe acute respiratory syndrome coronavirus 7a protein is dependent on its interaction with the $\mathrm{BCl}-\mathrm{XL}$ protein. J. Virol. 81, 6346-6355 (2007).
11. Hunot, S. et al. Nuclear translocation of NF-kappaB is increased in dopaminergic neurons of patients with Parkinson disease. Proc. Natl Acad. Sci. USA 94 7531-7536 (1997).

12. Flood, P. M. et al. Transcriptional factor NF-kB as a target for therapy in Parkinson's disease. Parkinsons Dis. 2011, 1-8 (2011).

13. Ridder, D. A. \& Schwaninger, M. NF-kB signaling in cerebral ischemia. Neuroscience 158, 995-1006 (2009).

14. Kilic, E., Dietz, G. P. H., Hermann, D. M. \& Bähr, M. Intravenous TAT-Bcl-XI is protective after middle cerebral artery occlusion in mice. Ann. Neurol. 52, 617-622 (2002)

15. Cao, G. et al. In vivo delivery of a BCl-xL fusion protein containing the TAT protein transduction domain protects against ischemic brain injury and neuronal apoptosis. J. Neurosci. 22, 5423-5431 (2002).

16. Pizzi, M. \& Spano, P. F. Distinct roles of diverse nuclear factor-kB complexes in neuropathological mechanisms. Eur. J. Pharm. 545, 22-28 (2006).

17. Srinivasan, M. \& Lahiri, D. K. Significance of NF-KB as a pivotal therapeutic target in the neurodegenerative pathologies of Alzheimer's disease and multiple sclerosis. Expert Opin. Ther. Targets 19, 471-487 (2015).

18. Chou, T. -C. Drug combination studies and their synergy quantification using the Chou-Talalay method. Cancer Res. 70, 440-446 (2010). 